\title{
Effects of waterjet cutting waste addition on properties of building ceramics
}

\author{
Natalia Skanavi ${ }^{1, *}$, and Timofei Dovydenko ${ }^{1}$ \\ ${ }^{1}$ Moscow State University of Civil Engineering, Yaroslavskoye shosse, 26, Moscow, Russia, 129337
}

\begin{abstract}
The purpose of the paper is to investigate the possibility of using wastes of waterjet metal cutting in the manufacture of building ceramics. A complex study of the composition and properties of the abrasive and hydroabrasive cutting wastes was carried out. The behavior of waste in the composition of the ceramic mass and the ceramic body was investigated. Positive results of the effect of addition of waste on the properties of ceramics were obtained on two types of polymineralic argillaceous raw materials: increase of strength at the optimum content of waste in the mixture, reduction of air and fire shrinkage in all compositions with waste content, possibility of varying the color of products, etc. The similarity of the chemical composition of argillaceous raw materials and wastes was established: oxides of iron, silicon and aluminum are predominant. Electron microscope research has demonstrated that the introduction of waste modifies the structure of the ceramic shard, but does not affect its uniformity. The obtained results allowed to draw conclusions about the possible use of wastes of waterjet metal cutting in the production of ceramics: as a fluxing agent - flux, component for volumetric staining, thinning agent.
\end{abstract}

\section{Introduction}

Investigation and involvement of new, previously unused production and consumption wastes in the production is a topical issue directly related to the conservation of natural resources and the protection of the biosphere from pollution. Such wastes include disperse industrial scrap formed during various types of metal cutting, shot-blasting of parts, operation of sandblasting chambers, during spraying, gas cleaning and so on. In terms of use of building materials in the production, these wastes are least studied or not studied at all.

We have considered the features of waterjet metal cutting, the composition and properties of the garnet abrasive and wastes [1,2]. A comprehensive study of the composition and properties of the waste has showed that they are very fine heavy sands with a high content of pulverized fraction, the chemical composition of which is dominated by oxides of iron, silicon and aluminum.

\footnotetext{
* Corresponding author: dovydenkotimofei@gmail.com
} 
In accordance with the Federal Classification Catalog of Waste (FCCW 2017), sand waste from waterjet cutting of ferrous and non-ferrous metals belongs to the hazard category 5, that is, practically unhazardous. According to the mechanism of formation and composition, these wastes correspond to mineral wastes and associated products that have not lost their natural properties, preserving the chemical and mineral composition of the corresponding rocks and natural minerals, and, accordingly, one can rely on the available recommendations for their preparation and use [3].

\subsection{Properties of waterjet metal cutting wastes}

Waterjet cutting generates wastes in the form of slurry containing an abrasive, particles of the cut metal. and water. The slurry is dehydrated, and the dry residue is stored in the enterprise and, as it accumulates, is transported to landfills of solid household waste.

The study of the dry part of the waste (homogenized mean sample) has produced the following results: true density $-3.92 \mathrm{~g} / \mathrm{cm}^{3}$, bulk density $-2.157 \mathrm{~g} / \mathrm{cm}^{3}$. The granulometric composition determined on a standard set of sand screens is mainly represented by two fractions: fine $(0.16 \div 0.315 \mathrm{~mm}-70.5 \%)$ and finest (less than $0.16 \mathrm{~mm}-27.1 \%)[1,2]$. We assumed that the finest waste fraction includes the particles of the cut metal, and this assumption was confirmed by the results of the study performed on a FEIQUANTA 200 scanning electron microscope $[1,4]$.

It was established that the true and bulk density essentially depend on the waste fraction. The particle size distribution determined on the standard ISO 3310-1 set of sieves and the true density of the individual fractions are presented in Table 1 . The largest value of the density of the smallest fraction also indirectly confirms the presence of metal.

Table 1. Comparison of the size distribution and high density of waterjet cutting wastes.

\begin{tabular}{|c|c|c|c|}
\hline $\begin{array}{c}\text { Sieve hole } \\
\text { dimensions, } \\
\mathbf{m m}\end{array}$ & $\begin{array}{c}\text { Individual } \\
\text { residues, \% }\end{array}$ & $\begin{array}{c}\text { Full residues, } \\
\mathbf{\%}\end{array}$ & $\begin{array}{c}\text { High density, } \\
\mathbf{g} / \mathbf{c m}^{3}\end{array}$ \\
\hline 0.25 & 10,3 & 10,3 & 3,65 \\
\hline 0.125 & 67.16 & 77.19 & 4.075 \\
\hline 0.063 & 13.33 & 90.79 & 4.04 \\
\hline$<0.063$ & 9.2 & 100 & 4.47 \\
\hline Total & 100 & - & - \\
\hline
\end{tabular}

The mineral composition is represented mainly by two minerals of the garnet group almandine $\mathrm{Fe}_{3} \mathrm{Al}_{2}\left(\mathrm{SiO}_{4}\right) 3-88.9 \%$ and pyrope $\mathrm{Mg}_{3} \mathrm{Al}_{2}\left(\mathrm{SiO}_{4}\right)_{3}-6.8 \%$. The remaining $4.3 \%$ account for ilmenite $\mathrm{FeTiO}_{3}-2.8 \%$ and quartz $\mathrm{SiO}_{2}-1.5 \%$. Three main oxides can be distinguished in the chemical composition: $\mathrm{Fe}_{2} \mathrm{O}_{3}-35.07 \% ; \mathrm{SiO}_{2}-31.02 \% ; \mathrm{Al}_{2} \mathrm{O}_{3}-$ $17.22 \%$. $\mathrm{TiO}_{2}$ and $\mathrm{MgO}$ also present in appreciable quantities - $7.62 \%$ and $6.74 \%$ respectively.

The above characteristics of waterjet cutting waste allowed us to outline possible ways of their use [1,2], one of which is the production of building ceramics.

\subsection{Preliminary study of the possibility of using wastes of waterjet metal cutting in the production of ceramics}


In order to study behavior of the waste (mainly the metal component) during calcinating in the composition of the ceramic mass, specimen cubes with an edge of $5 \mathrm{~cm}$ were made. A polymineral low-melting argillaceous raw material of the Novopodrezkovskoye deposit (vicinities of Moscow) [5] was used, whose mineral and chemical compositions are presented in Table 2.

Table 2. Mineral and chemical composition of argillaceous raw material for sample study

\begin{tabular}{|c|c|c|c|}
\hline \multicolumn{2}{|c|}{ Mineral composition } & \multicolumn{2}{c|}{ Chemical composition } \\
\hline Mineral & $\begin{array}{c}\text { Weight } \\
\text { content (\%) }\end{array}$ & Oxide & $\begin{array}{c}\text { Weight } \\
\text { content (\%) }\end{array}$ \\
\hline Quartz & 49 & $\mathrm{SiO}_{2}$ & 65.08 \\
\hline $\begin{array}{c}\text { Montmorillonite } \\
\text { Amorphous } \\
\text { phase }\end{array}$ & 25 & $\mathrm{Al}_{2} \mathrm{O}_{3}$ & 14.85 \\
\hline $\begin{array}{c}\text { Hydromica } \\
\text { Microcline }\end{array}$ & 5 & $\mathrm{Fe}_{2} \mathrm{O}_{3}$ & 11.65 \\
\hline Kaolinite & 3 & $\mathrm{~K}_{2} \mathrm{O}$ & 3.45 \\
\hline Hematite & 2 & $\mathrm{MgO}^{\mathrm{TiO}}$ & 1.98 \\
\hline Anorthite & 1 & $\mathrm{CaO}_{2}$ & 1.51 \\
\hline
\end{tabular}

Sample composition of the ceramic mass: $50 \%$ clay and $50 \%$ waste (by weight) with a water-soluble ratio of $18 \%$. Samples were dried at a temperature of $105{ }^{\circ} \mathrm{C}$, followed by calcinating at $900{ }^{\circ} \mathrm{C}$. No deformation of the samples, cracking, color anomalies were observed when calcinating. The average density of the samples after calcinating was 2.4 $\mathrm{g} / \mathrm{cm} 3$, water absorption - $11.6 \%$, compressive strength - $13.47 \mathrm{MPa}$. The color of the samples is red.

The mineral composition of the calcinated ceramic body lacks original argillaceous minerals (montmorillonite, hydromica, kaolinite), which underwent known temperature changes. The feldspar content (microcline, etc.), as well as the amorphous phase, have increased substantially (by $14 \%$ ). The almandine (13.5\%) and hematite (13.2\%), received from the waste, were also identified.

Preliminary research led to the conclusion that it is possible to use waste waterjet steel cutting for the manufacture of ceramic products.

There is evidence that the almandine decomposes at temperatures above $900{ }^{\circ} \mathrm{C}$ with the formation of a ferromagnetic sweat ball of hercinite, ferrous cordierite, and fayalite [6]. This possible process required additional research.

\section{Study of behavior of waterjet cutting wastes in the composition of raw mixture}

\subsection{Composition and properties of argillaceous raw materials}

Acidic low-melting argillaceous raw materials were used from the process line of the PAO GKZ, the chemical and mineral composition of which is presented in Table 3. This clayey rock is oversanded and is poor in clay-forming minerals. 
Table 3. Mineral and chemical composition of argillaceous raw materials of the PAO GKZ

\begin{tabular}{|c|c|c|c|}
\hline \multicolumn{2}{|c|}{ Mineral composition } & \multicolumn{2}{c|}{ Chemical composition } \\
\hline Mineral & $\begin{array}{c}\text { Weight } \\
\text { content (\%) }\end{array}$ & Oxide & $\begin{array}{c}\text { Weight } \\
\text { content (\%) }\end{array}$ \\
\hline Quartz & 56.6 & $\mathrm{SiO}_{2}$ & 69.99 \\
\hline Hematite & 5.7 & $\mathrm{Al}_{2} \mathrm{O}_{3}$ & 16.14 \\
\hline Albite & 11.9 & $\mathrm{Fe}_{2} \mathrm{O}_{3}$ & 5.36 \\
\hline Microcline & 10.8 & $\mathrm{~K}_{2} \mathrm{O}$ & 2.95 \\
\hline $\begin{array}{c}\text { Amorphous } \\
\text { phase }\end{array}$ & 15.0 & $\mathrm{MgO}$ & 2.02 \\
\hline- & - & $\mathrm{Na}_{2} \mathrm{O}$ & 1.27 \\
\hline- & - & $\mathrm{CaO}^{2}$ & 0.932 \\
\hline- & - & $\mathrm{TiO}_{2}$ & 0.836 \\
\hline
\end{tabular}

\subsection{Sample manufacture and testing}

In order to study the behavior of waterjet cutting wastes at a temperature above the temperature of the possible almandine decomposition, sample cubes with an edge of $4 \mathrm{~cm}$ from raw mixtures of various compositions were made.

Compositions of raw mixtures by weight: $20 \%$ clay and $80 \%$ waste, $40 \%$ clay and $60 \%$ waste, $65 \%$ clay and $35 \%$ waste and a mixture without waste. The water ratio for all wastes with waste was $18 \%$, and for pure clay raw materials the water-hard ratio required to achieve the lower limit of ductility was $25 \%$. Samples were dried and calcinated at $950{ }^{\circ} \mathrm{C}$.

Air shrinkage and average density were determined for the dried samples (Table 4). It was established that the greater the content of waste in the raw mix, the higher the average density of the raw material and the less air shrinkage, that is, at the drying stage, waterjet cutting waste addition behaves as a thinning agent.

Table 4. Air shrinkage and average sample density

\begin{tabular}{|c|c|c|}
\hline $\begin{array}{c}\text { Waste content by weight } \\
(\mathbf{\%})\end{array}$ & $\begin{array}{c}\text { Air } \\
\text { shrinkage } \\
(\mathbf{\%})\end{array}$ & $\begin{array}{c}\text { Average } \\
\text { density } \\
\left(\mathbf{g} / \mathbf{c m}^{\mathbf{3}}\right)\end{array}$ \\
\hline 0 & 12 & 2.03 \\
\hline 35 & 5 & 2.27 \\
\hline 60 & 4.58 & 2.37 \\
\hline 80 & 2.83 & 2.47 \\
\hline
\end{tabular}

No deformations or cracks were observed in the samples after calcinating. The color of the samples varied from light red in the wasteless composition to dark red-brown at the 
maximum content of waste in the mixture, which is associated with a high content of dyeing iron oxides in the waste.

Fire shrinkage, true and average density, porosity and strength of the ceramic shard were measured after calcinating, (Table 5).

Table 5. Physical and mechanical properties of ceramic samples

\begin{tabular}{|c|c|c|c|c|c|}
\hline $\begin{array}{c}\text { Waste } \\
\text { content by } \\
\text { weight }(\%)\end{array}$ & $\begin{array}{c}\text { Compressive } \\
\text { strength (MPa) }\end{array}$ & $\begin{array}{c}\text { Average } \\
\text { density } \\
\left(\mathrm{g} / \mathrm{cm}^{3}\right)\end{array}$ & $\begin{array}{c}\text { True } \\
\text { density } \\
\left(\mathrm{g} / \mathrm{cm}^{3}\right)\end{array}$ & Porosity (\%) & $\begin{array}{c}\text { Fire } \\
\text { shrinkag } \\
\text { e (\%) }\end{array}$ \\
\hline 0 & 10.69 & 1.79 & 2.68 & 33.07 & -1.07 \\
\hline 35 & 16.36 & 2.08 & 3.05 & 31.79 & -1.9 \\
\hline 60 & 10.29 & 2.17 & 3.35 & 35.28 & -2.79 \\
\hline 80 & 8.47 & 2.26 & 3.53 & 36.04 & -3.23 \\
\hline
\end{tabular}

With an increase in the waste content in the mixture, the average and true density of the samples are growing, which is due to the high density of the waste itself. There was a significant reduction in fire shrinkage: 1.8 times with a $35 \%$ waste content, and with a waste content of $80 \%$ - 3-fold, which indicates the deterrent effect of waste on possible volumetric changes during calcinating.

The introduction of waste in an amount of $60 \%$ practically does not affect the strength of the samples, and the optimum in terms of strength was the content of waste $35 \%$ - the strength increase was more than $50 \%$. A minimum porosity was observed in the same composition.

The determination of the mineral composition of the ceramic body revealed the presence of unchanged almandine in samples with waste content. This indicates that the calcinating temperature of $950{ }^{\circ} \mathrm{C}$ for these compositions and conditions was insufficient for the temperature transformations of almandine. However, with a good quality of the ceramic shard, a further increase in temperature would be not advisable.

\subsection{Electron microscope study of ceramic samples}

Electron microscope study has showed that the introduction of waterjet steel cutting does not adversely affect the uniformity of the structure of the ceramic body. Relatively large particles of garnet abrasive ( $300 \mu \mathrm{m}$ or less) are fairly evenly distributed in the volume of the body (Figure 1); the space between them is filled with a homogeneous ceramic stone, in which the calcinated clay substance, fine abrasive particles and particles of the cut metal are not visually separately determined. On large particles of abrasive, there is adherence of the smallest particles, which is clearly seen in Figure 2. With a large increase in the ceramic body with waste content, three types of particles are clearly distinguished: large (in the picture on the right), finest adhered to them represented mainly by particles of the cut metal $[1,2]$, and fine of different shapes and structures (layered, acute, rounded), but approximately the same in size. 


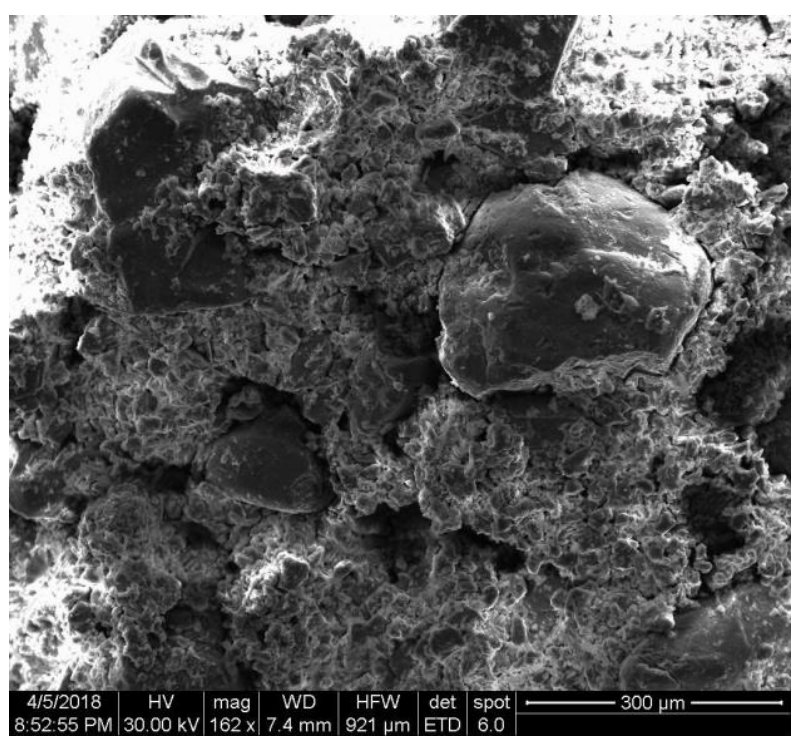

Fig. 1. Photomicrograph of a ceramic body with a waste content of $60 \%, \times 162$

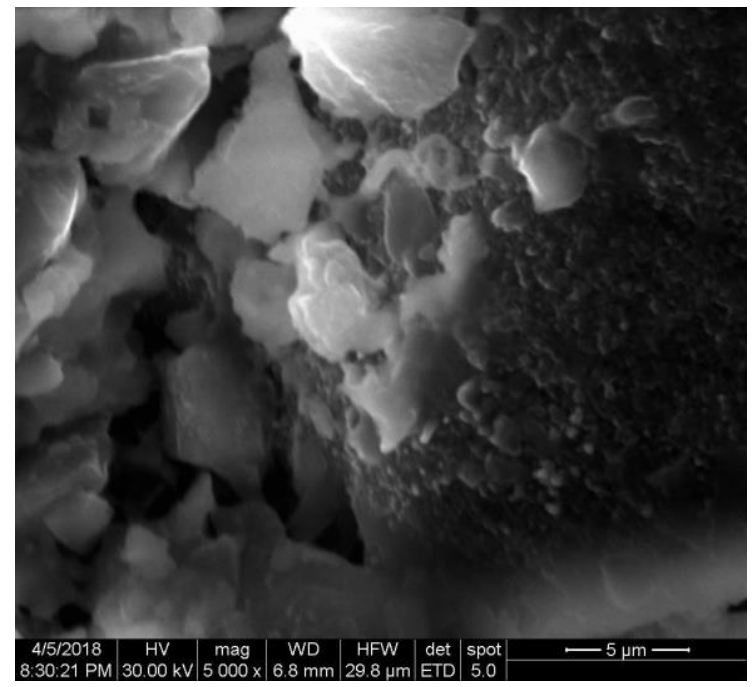

Fig. 2. Photomicrograph of a fragment of a ceramic body, $\times 5000$

The pickup of the cut metal particles to relatively large almandine particles may be due to the fact that the almandine, like other glandular garnets, has magnetic properties.

\section{Conclusions}

Waste waterjet steel cutting by composition and properties are well combined with the components of argillaceous raw materials, and play an active role in the composition of the ceramic mass and ceramic body: reduce air and fire shrinkage, increase the density and strength of the samples, allow to lower the calcinating temperature and to vary the color of the products. 
This allows us to conclude that it is possible to use the waste waterjet steel cutting for the manufacture of ceramic products as a polyfunctional component: flux agent (possibility of obtaining a high-quality ceramic body at $9000{ }^{\circ} \mathrm{C}$ and below), for volumetric staining (in view of the large chromophore content - iron oxide and cherry red almandine) and a thinning agent for ball clays.

It should be noted that the share of building ceramics in modern construction is projected to increase. In view of the shortage of conditioned raw materials, the trend is to work on artificial multicomponent homogenous furnace burdens, in which natural raw materials are often an insignificant fraction, and the main volume falls on industry-related raw materials, which is industrial waste [7]. Consequently, the use of wastes of waterjet metal cutting expands the raw material source for the production of building ceramics.

The trials have been performed at the laboratory of the Building Materials and Material Science Chair of the Moscow State University of Civil Engineering National Research University, The Head Regional Shared Research Facilities of the Moscow State University of Civil Engineering (RFMEFI59317X0006).

\section{References}

1. N. Skanavi, T. Dovydenko, MATEC Web of Conf., 117, 00041 (2017)

2. N. Skanavi, T. Dovydenko, Sci. Prospects, 4, 51 (2018)

3. P. Bozhenov, Complex use of mineral raw materials and ecology (ASV, Moscow, 265, 1994)

4. N. Skanavi, T. Dovydenko, Construction as Formation of the Living Environment, 801 (2017)

5. D. Zemlyanushnov, N. Sokov, D. Oreshkin, N. Skanavi, Vestnik of IrGTU, 9, 122 (2014)

6. F. Chukhrov,I. Ostrovsky, V. Lapina, Minerals. Diagrams of phase equilibria (Nauka, Moscow, 139, 1974)

7. S. Gabaldón, S. López, J.B. Carda, Key Eng. Mat., 264-268, 2517-2522 (2004) 